\title{
Layered double hydroxides for controlled fluoride release
}

Clarissiane Serafim CARDOSO(a) Johnnatan Duarte de FREITAS(b) Naile Roberta Lima dos SANTOS(c) Alexandre ALMEIDA JÚNIOR(d) (iD Irinaldo Diniz BASÍLIO JÚNIOR(c) Ticiano Gomes do NASCIMENTO(c) Luciano Aparecido Meireles GRILLO(c) Isabel Cristina Celerino de Moraes PORTO(e)

José Luis Gomes MARINHO(f)

Grazielle Emanuella de Souza dos SANTOS(f) (iD

Lucas MEILI(f) (iD

Fábio Correia SAMPAIO(g)

Camila Braga DORNELAS(c)

(a) Universidade Federal de Alagoas - UFAL, Institute of Biological Sciences and Health, Maceio, AL, Brazil.

(b) Instituto Federal de Alagoas - IFAL, Department of Chemistry, Maceio, AL, Brazil.

(c) Universidade Federal de Alagoas - UFAL, Pharmaceutical Science Institute, Maceio, AL, Brazil.

(d) Universidade Federal da Paraíba - UFPB, Oral Biology Laboratory, João Pessoa, PB, Brazil.

(e) Universidade Federal de Alagoas - UFAL, Faculty of Dentistry, Department of Restorative Dentistry, Maceio, AL, Brazil.

(f) Universidade Federal de Alagoas - UFAL, Technology Center, Maceio, AL, Brazil.

(g) Universidade Federal da Paraíba - UFPB, Department of Dentistry and Social Clinic, João Pessoa, PB, Brazil.

Declaration of Interests: The authors certify that they have no commercial or associative interest that represents a conflict of interest in connection with the manuscript.

Corresponding Author:

Camila Braga Dornelas

E-mail:dornelascb@yahoo.com.br

https://doi.org/10.1590/1807-3107bor-2021.vol35.0104

Submitted: August 13, 2019

Accepted for publication: January 21, 2021

Last revision: March 1, 2021
Abstract: This study aims to develop a nano-sized fluoridated layered double hydroxide (LDH)-based release system via hydrothermal treatment for the controlled delivery of fluoride $\left(\mathrm{F}^{-}\right)$ions in the oral environment. The synthesis of conventional LDH-type (C-LDH) precursor nanomaterials was conducted using a co-precipitation method at constant $\mathrm{pH}$, and the nanoparticulate-LDH (N-LDH) was synthesized by a hydrothermal procedure. Fluoride LDH (F-LDH) products were obtained through indirect synthesis using the precursor ion-exchange technique by varying the agitation time ( 2 and $24 \mathrm{~h}$ ) and temperature $\left(25\right.$ and $40{ }^{\circ} \mathrm{C}$ ) to produce 12 material samples. The materials were characterized by energy dispersive x-ray, hexamethyldisilazane, digital radiography x-ray, Fouriertransform infrared, thermogravimetric analysis, and scanning electron microscopy. Additionally, the F-release kinetic profile was evaluated for $21 \mathrm{~d}$ in neutral and acid media with mathematical model analysis. Products with varying F-quantities were obtained, revealing specific release profiles. In general, there was a higher F-release in the acid medium, with emphasis on F-LDH-8. Fluoride-LDH and controlled fluoride delivery was successfully obtained, proving the potential of these nanomaterials as alternative anti-caries agents.

Keywords: Dental Caries; Fluorine Compounds; Clay; Nanoparticles.

\section{Introduction}

Although a worldwide decline in caries has been observed, tooth decay remains a prevalent disease. Despite improvements in dental technology, dental caries affects children and adults regardless of their socioeconomic status. ${ }^{1}$ Insufficient fluoride use contributes to this issue. Fluoride presence can reduce demineralization (mineral loss) and increase dental remineralization. ${ }^{1,2}$ Therefore, it is essential to discuss efficient fluoride use and improve fluoride-releasing methods for better action in the oral environment. ${ }^{3}$

Multifunctional nanosystems have offered unique benefits related to nano-sized particles, including large surface area, dental biofilm penetration ability, and controlled drug delivery. ${ }^{4}$ Layered double hydroxides (LDHs), also known as anionic clays or hydrotalcite-like compounds, are nano-sized compounds. They are octahedron-shaped comprising hydroxyls forming lamellae and an ion-exchange switchable anion. ${ }^{5,6}$ 
These materials exhibit crystalline conformation and their composition depends on the cation type, molar ratio, and interlamellar anion type. ${ }^{5}$

Recently, LDH has been utilized as an adsorbent to remove excess fluoride ions from aqueous solutions via adsorption or ion exchange. ${ }^{7,8,9,10,11,12}$ In dentistry, LDHs are used for calcium release to target hydroxyapatite creation or zinc ion release to reduce demineralization. ${ }^{13,14}$ Additionally, LDHs have a non-soluble structure, which remains unchanged in dental material like toothpaste and mouthwash. ${ }^{15}$ Studies evaluating fluoridated LDH (F-LDH) for controlled fluoride ion release and dental applications have not been sufficiently explored. Thus, this study aims to develop a nano-F-LDHbased release system synthesized via hydrothermal treatment for the controlled delivery of fluoride $(\mathrm{F})$ ions in the oral environment.

\section{Methodology}

This study comprises F-LDH synthesis, its characterization, and fluoride release kinetic evaluation from synthesized materials. For this, 12 fluoridated products were obtained from the synthesis of conventional (C-LDH) and nanoparticulate (N-LDH) precursors. Each product was obtained by varying the agitation conditions and temperature, as shown in Table 1.

\section{Reagents}

Magnesium chloride $\left(\mathrm{MgCl}_{2}\right)$ and aluminum chloride $\left(\mathrm{AlCl}_{3}\right)$ hexahydrate were obtained from Sigma-Aldrich® Co. (USA). Sodium fluoride (NaF) was supplied by Merck (Germany).

\section{Precursors synthesis: C-LDH and N-LDH}

LDHs were synthesized using the direct co-precipitation method at constant $\mathrm{pH}$ and hydrothermal method in an autoclave/reactor for C-LDH and N-LDH, respectively. Both methods are described by the formula $\left[\mathrm{M}^{+2}{ }_{1-\mathrm{x}} \mathrm{M}^{+3}{ }_{\mathrm{x}}(\mathrm{OH})_{2}\right]^{\mathrm{d}} \mathrm{A}^{-}$ $\mathrm{m}_{\mathrm{x} / \mathrm{m}} \cdot \mathrm{nH}_{2} \mathrm{O}$, where $\mathrm{M}^{+2}$ and $\mathrm{M}^{+3}$ are bi and trivalent metal cations, respectively. ${ }^{5} \mathrm{MgCl}_{2}$ and $\mathrm{AlCl}_{3}$ were mixed in a 3:1 ratio. ${ }^{16,17}$ The solutions were stirred vigorously at room temperature. Following this, the products were centrifuged $(4500 \mathrm{rpm} ; 30 \mathrm{~min}$, Sigma 6-15, Rio de Janeiro, Brazil) and washed 4 to 7 times with Milli-Q water. The C-LDH was dried in an oven (NOVA instruments, São Paulo, Brazil) for $12 \mathrm{~h}$ at $60^{\circ} \mathrm{C}$. N-LDH was resuspended with Milli-Q water, and the obtained colloidal suspension was transferred to a reactor/autoclave (MAITEC - Fornos INTI, São Paulo, Brazil) to undergo hydrothermal treatment for $16 \mathrm{~h}$ at $100^{\circ} \mathrm{C}$ in an oven with air-forced circulation (NOVA instruments, São Paulo, Brazil) to obtain a final volume of $50 \mathrm{~mL}$. Half the suspension was reserved, and the other half was frozen at $-20^{\circ} \mathrm{C}$ for $48 \mathrm{~h}$ and subsequently freeze-dried (TERRONI ${ }^{\circledR}$

Table 1. Synthesis conditions

\begin{tabular}{|c|c|c|c|c|}
\hline Precursor & Handling condition & Agitation (h) & Temperature $\left({ }^{\circ} \mathrm{C}\right)$ & Product \\
\hline \multirow{4}{*}{ C-LDH } & \multirow{4}{*}{ Dried powder (oven) } & 2 & 25 & F-LDH/1 \\
\hline & & 2 & 40 & $\mathrm{~F}-\mathrm{LDH} / 2$ \\
\hline & & 24 & 25 & $\mathrm{~F}-\mathrm{LDH} / 3$ \\
\hline & & 24 & 40 & $\mathrm{~F}-\mathrm{LDH} / 4$ \\
\hline \multirow{4}{*}{$\mathrm{N}-\mathrm{LDH}$} & \multirow{4}{*}{ Colloidal suspension } & 2 & 25 & $\mathrm{~F}-\mathrm{LDH} / 5$ \\
\hline & & 2 & 40 & F-LDH/6 \\
\hline & & 24 & 25 & $\mathrm{~F}-\mathrm{LDH} / 7$ \\
\hline & & 24 & 40 & $\mathrm{~F}-\mathrm{LDH} / 8$ \\
\hline \multirow{4}{*}{ N-LDH } & \multirow{4}{*}{ Dried powder (freeze-drying) } & 2 & 25 & $\mathrm{~F}-\mathrm{LDH} / 9$ \\
\hline & & 2 & 40 & $\mathrm{~F}-\mathrm{LDH} / 10$ \\
\hline & & 24 & 25 & $\mathrm{~F}-\mathrm{LDH} / 11$ \\
\hline & & 24 & 40 & F-LDH/12 \\
\hline
\end{tabular}


LD1500, São Paulo, Brazil) following under $1 \mathrm{~mm} / \mathrm{h}$ with a $250 \mathrm{~mm} \mathrm{Hg}$ vacuum to obtain the powder. The colloidal suspensions and powders were reserved for characterization and the materials were used for fluoridated product synthesis.

\section{Fluoridated material synthesis}

F-LDHs were indirectly synthesized by the ion exchange technique. ${ }^{18}$ A $500 \mathrm{mg} / \mathrm{L} \mathrm{NaF}$ solution was mixed with two synthesized precursors types. ${ }^{15}$ According to Table 1, the stirring conditions ( 2 and 24 h) and the temperatures $\left(25\right.$ and $\left.40^{\circ} \mathrm{C}\right)$ were varied to obtain 12 products. The materials were centrifuged, washed thrice with deionized water, dried in an oven (NOVA instruments, São Paulo, Brazil) for $3 \mathrm{~h}$ at $60^{\circ} \mathrm{C}$, and reserved for characterization. Potentiometry analysis was conducted to confirm the synthesis. This utilized a specific fluoride iron electrode (Orion 9409) by the hexamethyldisiloxane (HMDS)-facilitated microdiffusion technique, following a modified Taves method (1968). . $^{19,20}$

The HMDS analysis consisted of placing the analite (powder of the 12 materials, $0.025 \mathrm{~g}$ ) in individual polystyrene Petri dishes $(60 \times 15 \mathrm{~mm})$ that serve as an alkaline trap for fluoride. All procedures were duplicated. First, a small hole $( \pm 2 \mathrm{~mm})$ was burned into the lid of polystyrene Petri dishes $(60 \times 15 \mathrm{~mm})$. Then, the internal lid periphery was ringed with petroleum jelly for the posterior seal. The alkaline trap consisted of five $\mathrm{NaOH}$ drops $(0.05 \mathrm{M})$ carefully placed in the inner part of the lid. The lid was fixed on a Petri dish by sealing the system. Finally, $2 \mathrm{~mL}$ of 3 M HMDS-saturated sulfuric acid was added through the hole in the lid, which was sealed with petroleum jelly.

After overnight agitation (Orbital Gyratory Shaker TE-141, Tecnal, São Paulo, Brazil), the lids were carefully removed and the $\mathrm{NaOH}$ fluoride trap was buffered with $25 \mu \mathrm{L}$ of $0.2 \mathrm{M}$ acetic acid. The total volume was adjusted to $75 \mu \mathrm{L}$ by adding deionized water and the same pipette was used to mix the solution.

The final drop fluoride was analyzed using a halfcell ion-specific (Orion Research, Cambridge, MA, USA, model 9409) and calomel reference electrode (Accumet model 13620-79). Both electrodes were coupled to a microprocessor ionalyser (Orion Research, model 710A, Cambridge, USA).

The calibration curve was obtained using five standards with known fluoride contents prepared by serial dilution from a $100 \mathrm{mg}$ F/L stock solution (Orion Research, \# 940907, Cambridge, USA): 0.01, 0.02, $0.04,0.08$, and $0.16 \mu g F$. These standards were diffused in triplicate like for the samples. The millivoltage potentials were converted to $\mu \mathrm{gF}$ using Microsoft Office Excel and an $r>0.99$ correlation coefficient was accepted. The mean repeatability of the duplicate sample readings was above $90 \%$.

\section{Characterization}

Dispersive energy $x$-ray fluorescence spectrometry (EDX) was performed by a Shimadzu Spectrometer EDX 7000 under vacuum with a $10 \mathrm{~mm}$ collimator for $\mathrm{Mg}, \mathrm{Al}$, and $\mathrm{Cl}$ quantification. As EDX does not quantify elements with low atomic numbers, the fluoride ion quantification (total fluoride) was assessed according to the Taves method $(1968)^{19}$ by indirectly facilitated hexamethyldisiloxane (HMDS) microdiffusion through an Orion-specific ion electrode 9409 coupled to a potentiometer (Orion, 720 A). X-ray diffraction (XRD) was performed using a Shimadzu $\mathrm{X}$-ray diffractometer, using $\mathrm{Cu} \mathrm{K} \alpha$ radiation at 30 $\mathrm{mA}$ and $30 \mathrm{kV}$, in a $0.02^{\circ}(2 \theta)$ range from $3^{\circ}$ to $90^{\circ}$. The basal spacing $\mathrm{d}(003)$ was calculated using the Bragg equation $(n \cdot \lambda=2 \cdot d \cdot \sin \theta)$. Fourier-transform infrared spectrometry (FTIR) was conducted using a spectrometer (Thermo Scientific Nicolet ${ }^{\mathrm{TM}} \mathrm{iS}^{\mathrm{TM}} 10$ ) in the $4000-500 \mathrm{~cm}^{-1}$ range, using potassium bromide tablets (KBr); $2 \mathrm{mg}$ sample and $200 \mathrm{mg}$ dry $\mathrm{KBr}$. Thermogravimetric analysis (TGA) was performed using a Shimadzu TGA-50 thermoanalyzer (Kyoto, Japan), at a $10{ }^{\circ} \mathrm{C} / \mathrm{min}$ heating rate in a $50 \mathrm{~mL} / \mathrm{min}$ nitrogen gas flow from 25 to $800{ }^{\circ} \mathrm{C}$. Micrographs were obtained using scanning electron microscopy (SEM) from the TESCAN-VEGA3. The samples were previously coated with gold in a QUORUM- Q150R ES metallizer at a $10 \mathrm{~mA}$ current for $10 \mathrm{~min}$.

\section{Fluoride release kinetics}

Fluoride release kinetics analysis was conducted for $21 \mathrm{~d}$. The specimens $\left(4.3 \mathrm{~cm}^{2}\right)$ were individually distributed in plastic vials, then immersed in deionized 
water $(\mathrm{pH} 7)$ and a sulfuric acid $(\mathrm{pH}=5.5)-\mathrm{H}_{2} \mathrm{SO}_{4}$ solution. ${ }^{21}$ Sulfuric acid was used to acidify the solution medium to maintain the HMDS acidic conditions.

The fluoride amount was measured at predetermined time intervals $(1,2,3,5,7,14$, and 21 days). For F-released determination, $1 \mathrm{~mL}$ of the sample (F-LDH) was used with $1 \mathrm{~mL}$ total ionic strength adjustment buffer II (TISAB II). The standard solutions were prepared in triplicate under conditions similar to that of the samples $(0.4-6.4 \mathrm{mg} \mathrm{F} / \mathrm{mL})$. The calibration and concentrations were determined by testing a linear regression curve using the Excel software. The electrode potential was related to the logarithm of the measured ion concentration by the Nernst equation. This program transformed the $\mathrm{mV}$ values provided by the electrode to $\mathrm{ppm}$ ( $\mu \mathrm{g} \mathrm{F} / \mathrm{mL}$ ). For each fluoride material, two fluoride release experimental repetitions were conducted. 24 samples were obtained for neutral and acid media, each. Finally, the 48 F-contained solutions released were analyzed in duplicate and the analyses were validated using internal standards. A coefficient variation under $5 \%$ was considered acceptable.

The kinetics data were converted into percentages from total fluoride (HMDS) quantification (ppm). To investigate the release mechanism, the obtained data were analyzed using the following mathematical models: zero-order kinetics (Equation 1), first-order kinetics (Equation 2), Higuchi (Equation 3), and Korsmeyer-Peppas (Equation 4). Statistical calculations were performed using the non-linear regression module Statistica 13.3 software by the Quasi-Newton method with lamellar LDH geometry. ${ }^{22}$

$\mathrm{q}_{\mathrm{t}}=\mathrm{k}_{\mathrm{Z}}{ }^{\mathrm{t}} \mathrm{t}$

$q_{t}=q_{e}{ }^{*} \exp \left(-k_{F}{ }^{*} t\right)$,

$\mathrm{q}_{\mathrm{t}}=\mathrm{k}_{\mathrm{H}} * \sqrt{\mathrm{t}}$

$\frac{M_{t}}{M_{\infty}}=k_{P} * t^{n}$

where $q_{t}$ is the amount of drug dissolved in time $(t), q_{e}$ is the initial amount of drug in the solution, $\mathrm{k}_{\mathrm{z}}$ is the zero-order release kinetic constant, $\mathrm{k}_{\mathrm{F}}$ is the firstorder release kinetic constant, $\mathrm{k}_{\mathrm{H}}$ is the Higuchi release kinetic constant, $\mathrm{M}_{\mathrm{t}}$ is the cumulative amount of drug released in time $(\mathrm{t})$, and $\mathrm{M}_{\infty}$ is the initial drug loading.

\section{Results}

The EDX analysis results are presented in Table 2, which confirm the C-LDH and N-LDH formation. In addition to the presence of $\mathrm{Cl}$ in the precursors, the $\mathrm{Mg} / \mathrm{Al}$ ratio of approximately 3:1 was ratified.

The HMDS technique allowed fluoride quantification in all analyzed samples (Table 2). The total fluoride quantification values, referring to $100 \%$ $\mathrm{F}$ present in fluoridated products, are presented in Table 2. For F-LDH-1 to -4 materials, chloride (Cl) was quantified in smaller proportions when compared to the precursor (C-LDH). For materials synthesized with $\mathrm{N}-\mathrm{LDH}$ nanoparticulate precursor using the colloidal suspension, the chloride ion was quantified at $\approx 1 \%$. Only the F-LDH-8 sample reproduced the results of F-LDH-9 to -12, which utilized the chlorinated precursor in lyophilized powder form. The chloride ions were not quantified for these products.

The diffractograms of the precursors C-LDH and N-LDH are shown in Figures 1(A) and 1(B),

Table 2. Constitution of elements present in the studied samples.

\begin{tabular}{lccc}
\hline Sample & $\mathrm{Mg} / \mathrm{Al}(\%)$ & $\mathrm{Cl}(\%)$ & $\mathrm{F}(\mu \mathrm{g} / \mathrm{mL}$ F) \\
\hline C-LDH & 2.76 & 9.6 & - \\
$\mathrm{N}-\mathrm{LDH}$ & 2.80 & 5.7 & - \\
F-LDH/1 & 2.50 & 1.5 & 971.5 \\
F-LDH/2 & 2.41 & 1.7 & 979.2 \\
F-LDH/3 & 2.41 & 1.3 & 561.6 \\
F-LDH/4 & 2.60 & 1.3 & 1097.5 \\
F-LDH/5 & 2.80 & 1 & 594.1 \\
F-LDH/6 & 3.50 & 1 & 739.2 \\
F-LDH/7 & 3.20 & 0.9 & 510.1 \\
F-LDH/8 & 3.20 & - & 610 \\
F-LDH/9 & 3.00 & - & 730 \\
F-LDH/10 & 2.40 & - & 851 \\
F-LDH/11 & 2.75 & - & 123.1 \\
F-LDH/12 & 2.60 & - & 635 \\
\hline
\end{tabular}

$\mathrm{Mg} / \mathrm{Al}$ : molar ratio of magnesium and aluminum; $\mathrm{Mg}, \mathrm{Al}$, and $\mathrm{Cl}$ were obtained using EDX; the $\mathrm{F}^{-}$ion was determined by HMDS. 

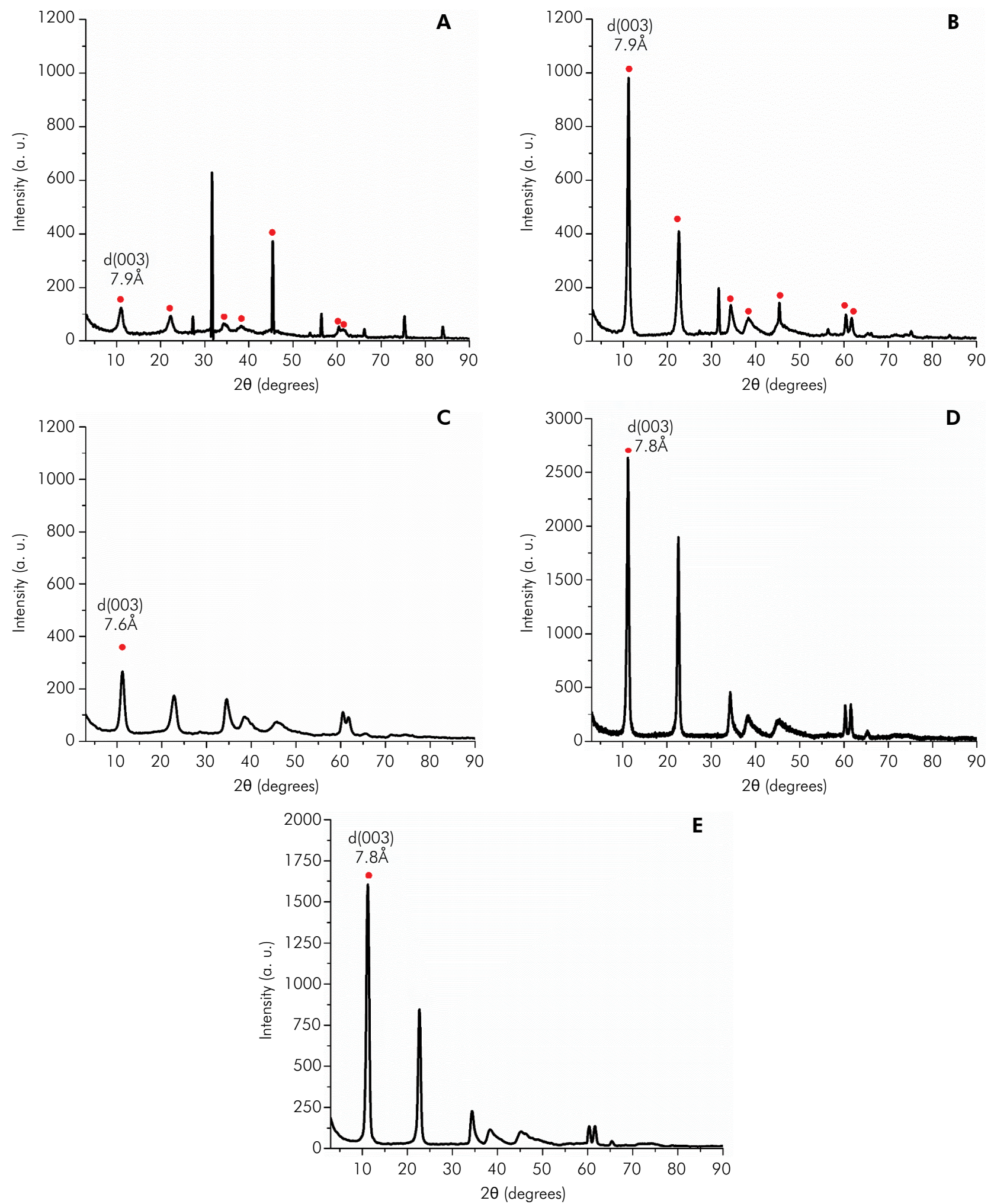

Figure 1. Diffractograms of precursors C-LDH (A) and N-LDH (B). (C), (D), and $€$ illustrate the diffractograms of F-LDH synthesis at $25^{\circ} \mathrm{C}$ for $2 \mathrm{~h}$. Fluoride product (F-LDH/1) synthesis from C-LDH precursor (C). Fluoride product (F-LDH/5) synthesis from N-LDH colloidal suspension (D). Fluorinated product (F-LDH/9) synthesis from N-LDH powder (E). Note, the baseline spacing d (003) value was $7.9 \AA$ for both precursors. Fluoride products showed a reduction $(7.6 \AA$ and $7.8 \AA)$. The crystallographic pattern similarity in all materials was studied. 
and the F-LDH product diffractograms are shown in Figures 1(C), 1(D), and 1(E). According to Figure 1, the obtained materials presented basal plane characteristics of the studied material under a $25^{\circ} \mathrm{C}$ and $2 \mathrm{~h}$ condition.

The infrared spectra shown in Figure 2 revealed bands centered at 3445, 1638, 2056, 1355, 1097, and $\sim 600 \mathrm{~cm}^{-1}$.

Figure 3 depicts the thermal degradation, where the different fluoridated sample behaviors of the fluoride-free samples can be observed.

The SEM micrographs in Figures 4(A-E) reveal particles with irregular and rough surfaces.

\section{Fluoride release kinetics}

Figure 5 shows the fluoride release kinetic curves for neutral and acidic media. The fluoride release pattern was similar for all products; however, minor differences in the amount of fluoride released for each material, comprising log release profiles, implied higher quantifiable anion values in the acidic medium. Among all products, F-LDH-9 presented 6.0\% release values $(64 \mu \mathrm{g} / \mathrm{mL} \mathrm{F})$ in both media and F-LDH-11 exhibited the highest $\mathrm{F}^{-}$amount as the experiment ended: $45.7 \%$ (56.32 $\mu \mathrm{g} / \mathrm{mL}$ F, $\mathrm{pH}=7.0)$ and $46.6 \%(57.40$ $\mu \mathrm{g} / \mathrm{mL}$,, $\mathrm{pH}=5.5$ ) (Figures 5(A-B)). Moreover, Tables 3 and 4 summarize all estimated kinetic parameters with the determination coefficient (R2) based on the experimental data from Equations 1-4 for the neutral and acid media, respectively. The adjusted kinetic model results showed that F-LDH-8 (24 h synthesis at $40^{\circ} \mathrm{C}$ ) exhibited a better $\mathrm{F}$ release in the acidic medium following a Fick model, whereas, in a neutral medium, a non-Fick behavior was observed.

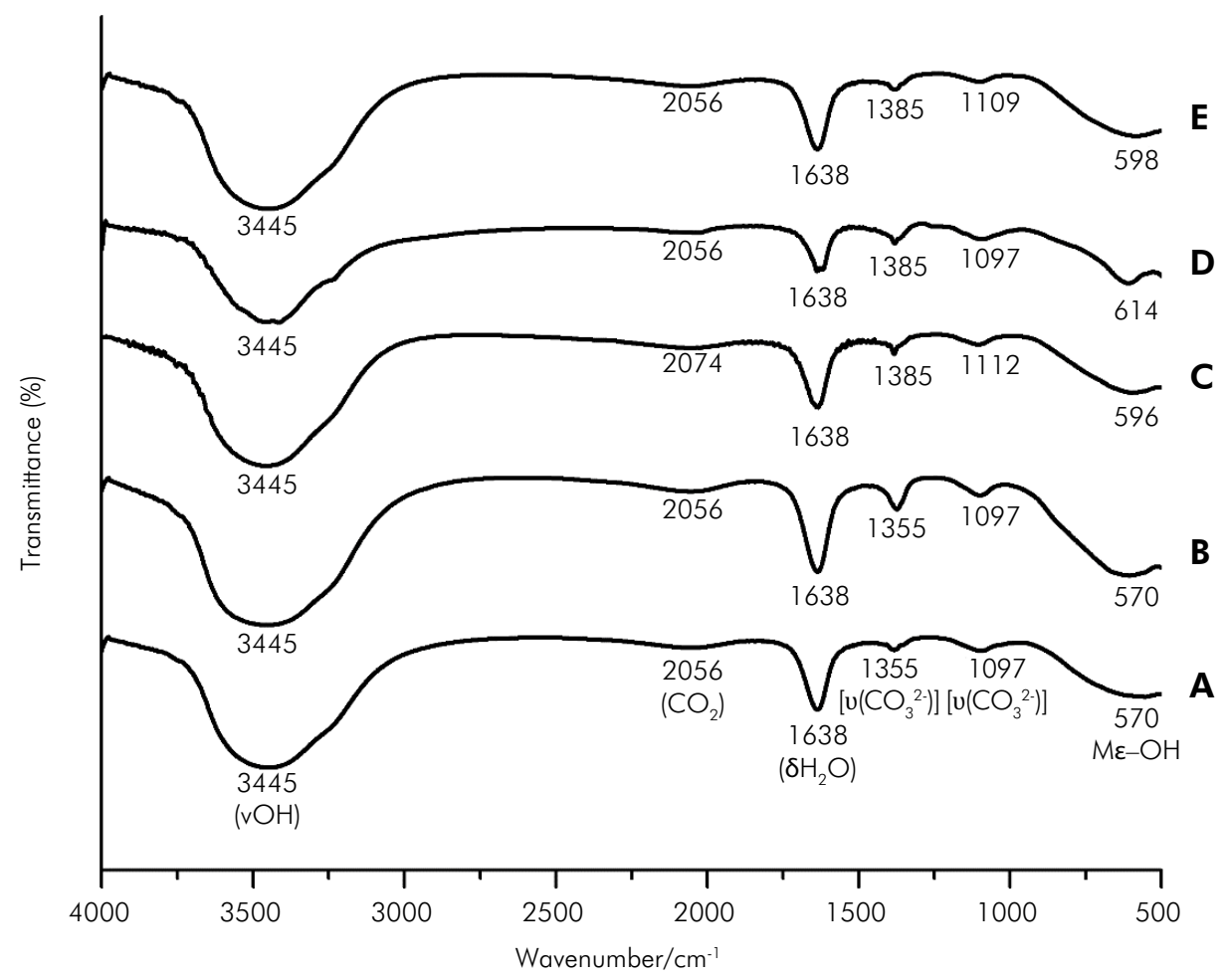

Figure 2. Infrared spectra of precursors $C-L D H(A)$ and $N-L D H(B) .(C),(D)$, and (E) illustrate the infrared spectra of F-LDH synthesis at $25^{\circ} \mathrm{C}$ for $2 \mathrm{~h}$. Fluoride product $(\mathrm{F}-\mathrm{LDH} / \mathrm{l})$ synthesis from C-LDH precursor (C). Fluoride product (F-LDH/5) synthesis from N-LDH colloidal suspension (D). Fluorinated product (F-LDH/9) synthesis from N-LDH powder (E). Absorptions associated with asymmetric axial and angular deformation of the hydroxyl group $\left(\mathrm{vOH}-3445 \mathrm{~cm}^{-1} ; \delta \mathrm{H}_{2} \mathrm{O}-1638 \mathrm{~cm}^{-1}\right)$ bonds correspond to the adsorbed and interlamellar water molecules, respectively. At approximately $2056 \mathrm{~cm}^{-1}$, there is a band corresponding to a $\mathrm{CO}_{2}$ medium. $1355 \mathrm{~cm}^{-1}$ and $1097 \mathrm{~cm}^{-1}$ correspond to asymmetric axial stretching and deformation mode of the carbonate anion $\left[\mathrm{v}\left(\mathrm{CO}_{3}{ }^{2-}\right)\right]$. The band at $600 \mathrm{~cm}^{-1}$ is related to the metal presence. Note, for (C), (D), and (E), the corresponding fluoride products showed a higher band frequency relative to $\mathrm{CO}_{3}^{2-}\left(1385 \mathrm{~cm}^{-1}\right)$. 


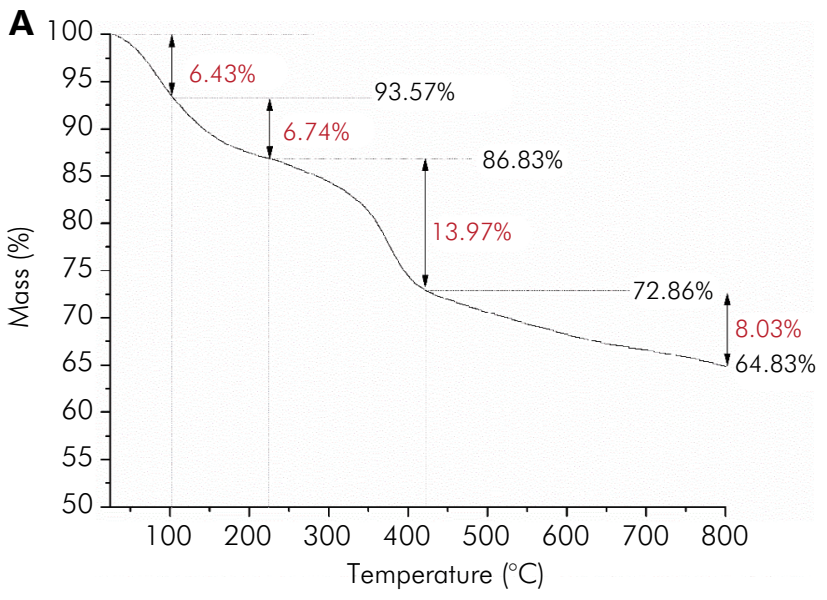

C

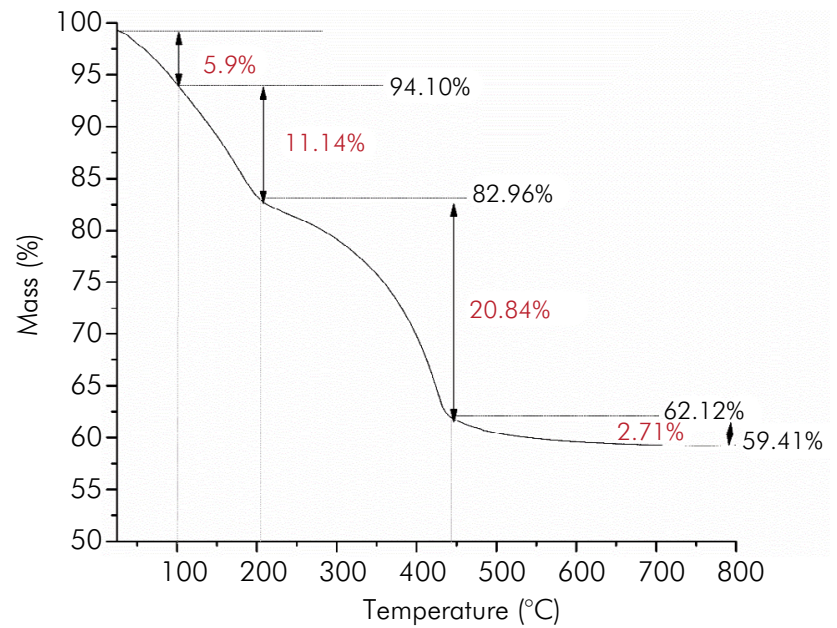

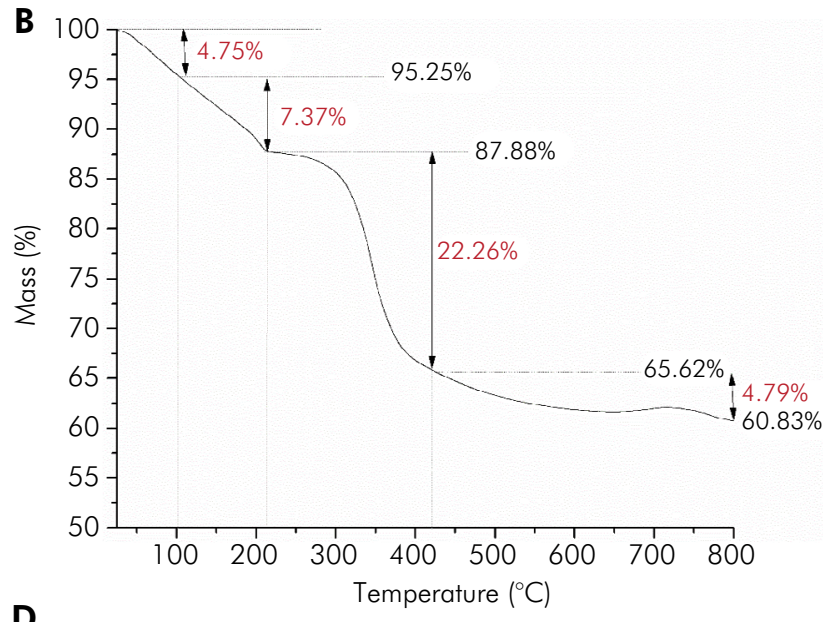

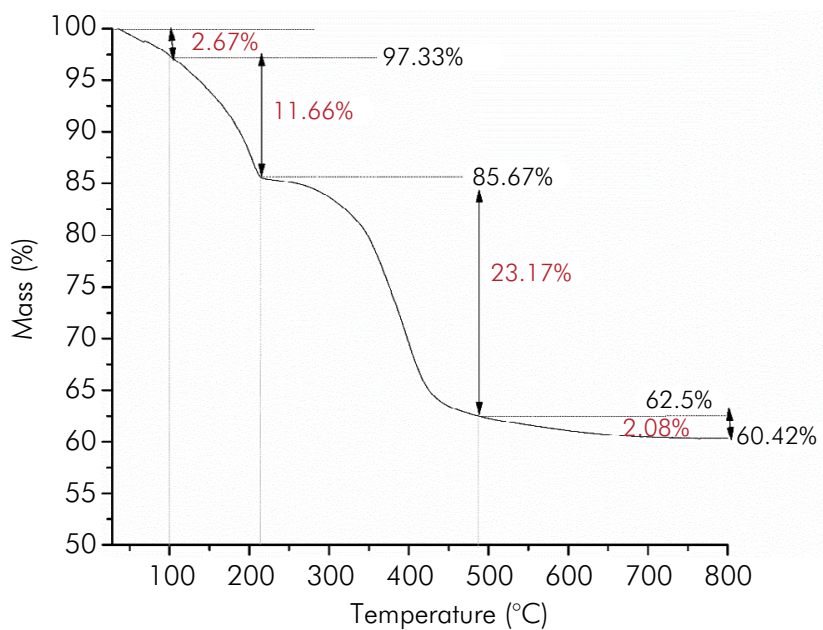

$\mathbf{E}$

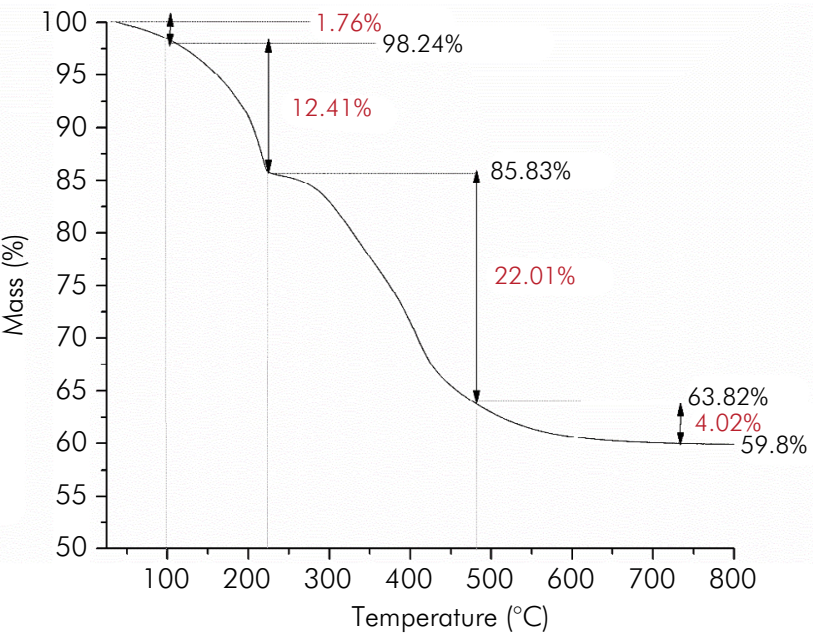

Figure 3. Thermal degradation curves of precursors C-LDH (A) and N-LDH (B). (C), (D), and (E) illustrate the TGA of F-LDH synthesis at $25^{\circ} \mathrm{C}$ for $2 \mathrm{~h}$. Fluoride product (F-LDH/1) synthesis from C-LDH precursor (C). Fluoride product (F-LDH/5) synthesis from $\mathrm{N}$-LDH colloidal suspension (D). Fluorinated product (F-LDH/9) synthesis from N-LDH powder (E). Note, an initial mass loss occurs between 25 and $200^{\circ} \mathrm{C}$ (volatilization of adsorbed water and interlamellar water, respectively). For $200-430^{\circ} \mathrm{C}$ and $450-800^{\circ} \mathrm{C}$, the third and fourth decomposition stages show structural dehydroxylation and loss of $\mathrm{CO}_{2}$ and consequently, the lamellar structure, respectively. For fluoride products, higher decomposition temperatures are required for material degradation ((C), (D), and (E)). 

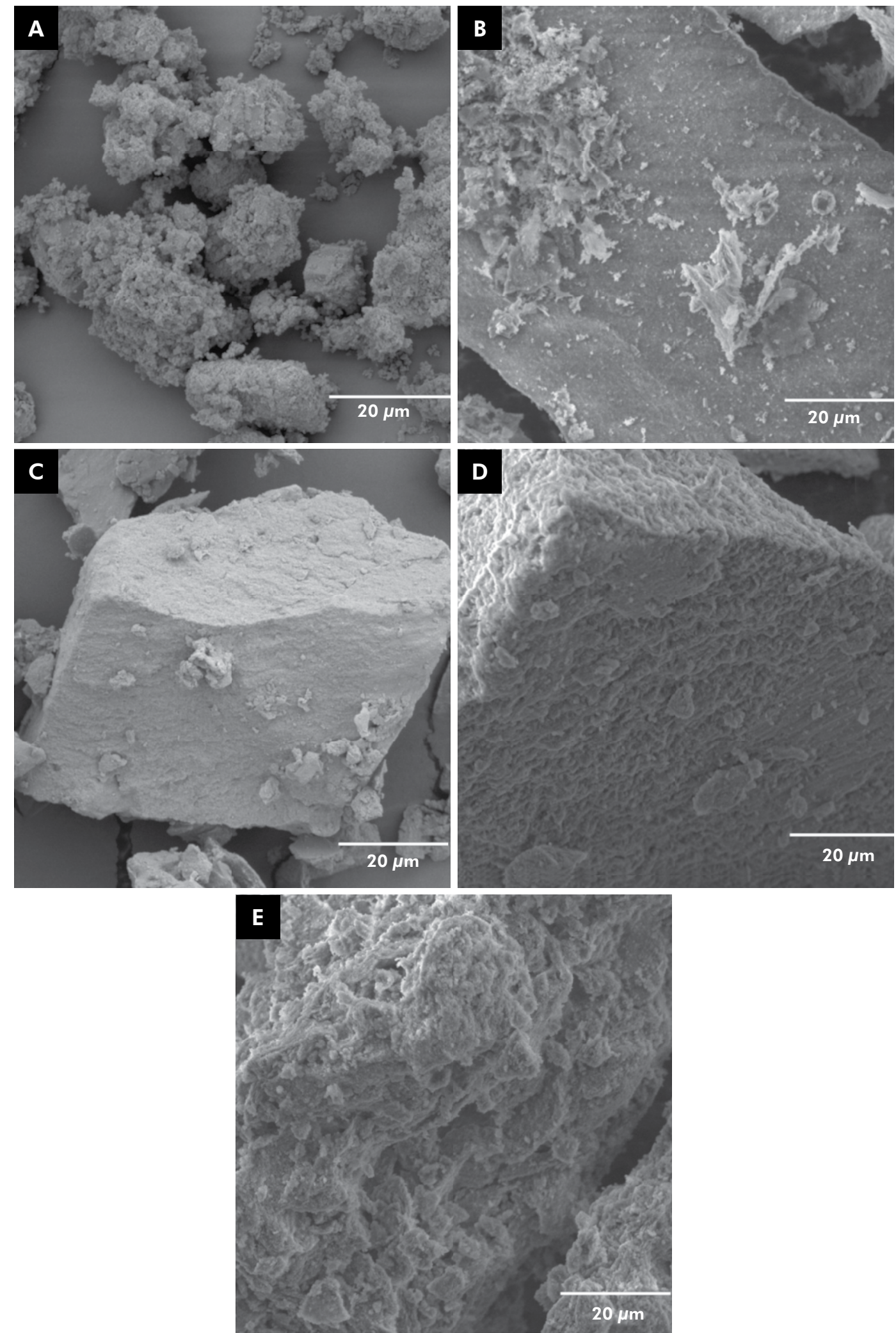

Figure 4. SEM photomicrograph illustrates the precursors C-LDH (A) and N-LDH (B). (C), (D), and (E), illustrate the SEM of F-LDH synthesized at $25^{\circ} \mathrm{C}$ for $2 \mathrm{~h}$. Fluoride product (F-LDH/1) synthesis from C-LDH precursor (C). Fluoride product (F-LDH/5) synthesis from N-LDH colloidal suspension (D). Fluorinated product (F-LDH/9) synthesis from N-LDH powder (E). Note, the particle SEM micrographs show irregular and rough surfaces. 

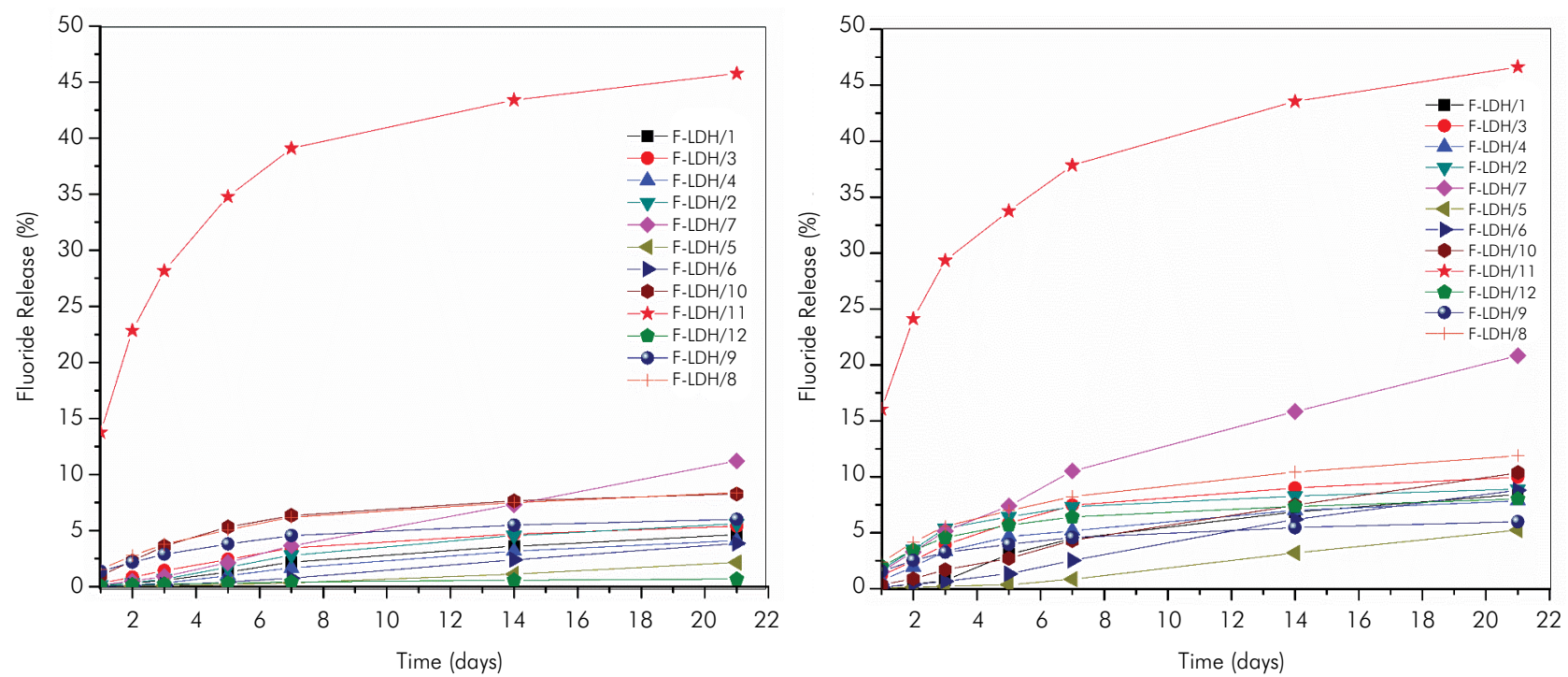

Figure 5. Kinetic curves for fluoride $\left(F^{-}\right)$release for all samples. Neutral $(A)$ and acidic (B) mediums. Note, the acid medium showed a higher F-amount among all F-LDH/1 1 products synthesized (at $25^{\circ} \mathrm{C}$ for $24 \mathrm{~h}$ ) from the $\mathrm{N}$-LDH powder. It showed the best value: $45.7 \%(\mathrm{pH}=7.0)(\mathrm{A})$ and $46.6 \%(\mathrm{pH}=5.5)(\mathrm{B})$.

\section{Discussion}

This is a novel study conducted with fluorideloaded LDHs for controlled release, using hydrothermal-treated LDH nanoparticulates under high pressure and temperature. LDHs are capable of anionic exchange; thus, they have attracted interest as promising materials for several applications. $\mathrm{LDH}$ is biocompatible and has been studied for numerous biological purposes, including controlled release systems. In dentistry, calcium release in hydroxyapatite or zinc ion formation is beneficial. Additionally, small crystals may be used to control dental hypersensitivity, occluding the dentinal tubules. LDH can adsorb and release fluoride that controls the carious process, which was the subject of this study. ${ }^{15}$

The EDX analysis provided the material elemental composition without revealing specific organic composition results of the respective elements. The EDX results suggest a partial anion exchange of $\mathrm{Cl}^{-}$by $\mathrm{F}^{-}$. A total anion exchange of $\mathrm{Cl}^{-}$by $\mathrm{F}^{-}$for F-LDH-9 to -12 was observed and confirmed by potentiometry analysis.

Figures 1(A) and 1(B) display diffractograms similar to that of the crystallographic pattern of clay seen in previous literature. ${ }^{23}$ The basal spacing d (003) value for all LDH precursors was $7.9 \AA$, which is similar to the values reported in studies for chloride presence. ${ }^{22,24} \mathrm{All}$ F-LDH products presented the same reduction behavior of the basal spacing relative to the precursor $(\mathrm{d}(003)=7.9 \AA$ to $7.8 / 7.6 \AA)$, regardless of synthesis procedures, corroborating with the literature. ${ }^{910,13,18,25}$ An increase in the F-LDH crystallinity was observed as compared to that of C-LDH, which indicates the ordered accommodation of $\mathrm{F}^{-}$within the interlamellar region. ${ }^{18} \mathrm{~F}-\mathrm{LDH}-5$ (Figure 1(D)) synthesized from colloidal suspension showed greater crystallinity as compared to that of N-LDH (colloidal suspension and powder). This suggested freeze-drying process interference with the property, as previously reported. ${ }^{26}$

The FTIR analysis revealed bands centered at 3445 $\mathrm{cm}^{-1}$ and $1638 \mathrm{~cm}^{-1}$, which are characterized by an asymmetric axial $(\mathrm{vOH})$ and angular $\left(\mathrm{SH}_{2} \mathrm{O}\right)$ hydroxyl group deformation corresponding to the adsorbed or interlamellar water molecules. The $2056 \mathrm{~cm}^{-1}$ band corresponds to the $\mathrm{CO}_{2}$ medium. ${ }^{24,27}$ Additionally, there were weak bands at $1355 \mathrm{~cm}^{-1}$ and $1097 \mathrm{~cm}^{-1}$, which is attributed to the asymmetric axial stretching or deformation mode of the carbonate anion $\left[\mathrm{v}\left(\mathrm{CO}_{3}{ }^{2-}\right)\right]$, formed due to atmospheric $\mathrm{CO}_{2}$ absorption during washing. ${ }^{28,29}$ At $600 \mathrm{~cm}^{-1}$, the bands related to metal, 
$\mathrm{Mg}$ and $\mathrm{Al}$, presence were observed bound to hydroxyl groups. ${ }^{2,3,30}$ When fluoride ion intercalation occurs, the band relative to the $\mathrm{CO}_{3}{ }^{2-}\left(1355 \mathrm{~cm}^{-1}\right)$ shifts to a higher frequency, comprising values centered on $1385 \mathrm{~cm}^{-1}$ (Figure 2(A)-(E)).,18

In general, TGA revealed an initial mass loss between 25 and $200^{\circ} \mathrm{C}$, corresponding to the phases: volatilization of adsorbed water (up to $100^{\circ} \mathrm{C}$ ) and interlamellar water (up to $200^{\circ} \mathrm{C}$ ). The third and fourth decomposition stages occurred at approximately $200-430^{\circ} \mathrm{C}$ and $450-800^{\circ} \mathrm{C}$, respectively. This was related to structural dehydroxylation and $\mathrm{CO}_{2}$ loss, with the consequent loss of the lamellar structure. ${ }^{23,24}$ In the last two steps, fluoride presence is clear as higher temperatures are necessary for material degradation. This is explained by the formation of strong hydrogen bonds, which increases the interaction between molecules and restricts structural loss, showing that the fluoridated samples are more stable (Figures 3(A)-(E)). ${ }^{3,25,27}$ According to SEM micrographs, the particles have irregular and rough surfaces, as described in previous literature (Figures 4(A)-(E)). ${ }^{3,4}$

For the F-release kinetic profiles of the fluoridated samples (Figures 5(A)-(B)), the analysis revealed the potential use of this material in dentistry. Slow and fast fluoride releases from synthesized materials were observed, thus proving the applicability of the material. According to the literature, the main anti-caries effect occurs when the material is present in the oral medium in its free (ionic) soluble form. Its high continuous concentration in the buccal environment is an excellent advantage for demineralization and dental remineralization. . $^{31,32}$

Most products exhibited a high amount of fluoride release in acidic medium, except for two: F-LDH-9 with a $6.0 \%$ release value $(64 \mu \mathrm{g} / \mathrm{mL}$ F) in both media and F-LDH-11 with $45.7 \%(56.32 \mu \mathrm{g} / \mu \mathrm{g} / \mathrm{mL}$ F) and $46.6 \%(57.40 \mu \mathrm{g} / \mu \mathrm{g} / \mathrm{mL}$ F) release values in neutral and acidic media, respectively. These products, however, did not differ in $\mathrm{pH}$ change. Despite their crystalline structure, these characteristics corroborate with their diffractograms. They are less intense when compared to products from the precursor in suspension and configure a lower fluoride accommodation in the interlamellar space. ${ }^{19}$ This suggests greater anion availability by setting similar release values. Moreover, such products were obtained at room temperature and, as seen in the thermal analysis, fluoridated products need higher temperatures for degradation. ${ }^{25,33}$ These products were more unstable, less crystalline, and independent of the $\mathrm{pH}$ value, at room temperature.

The highest $\mathrm{R}^{2}$ was obtained from the KorsmeyerPeppas model (Tables and 3 and 4). In both media, the

Table 3. Estimated kinetic parameters of drug release (Neutral medium).

\begin{tabular}{|c|c|c|c|c|c|c|c|c|c|}
\hline \multirow{3}{*}{ Sample } & \multicolumn{9}{|c|}{ Kinetic model } \\
\hline & \multicolumn{2}{|c|}{ Zero-order } & \multicolumn{2}{|c|}{ First-order } & \multicolumn{2}{|c|}{ Higuchi } & \multicolumn{3}{|c|}{ Korsmeyer-Peppas } \\
\hline & $\mathrm{K}_{\mathrm{z}}$ & $R^{2}$ & $\mathrm{~K}_{\mathrm{F}}$ & $R^{2}$ & $\mathrm{~K}_{\mathrm{H}}$ & $\mathrm{R}^{2}$ & $n$ & $K_{p}$ & $R^{2}$ \\
\hline $\mathrm{F}-\mathrm{HDL} / \mathrm{l}$ & 23.291 & 0.9741 & -0.0928 & 0.8489 & 83.300 & 0.8483 & 0.8956 & 0.0032 & 0.9766 \\
\hline $\mathrm{F}-\mathrm{HDL} / 2$ & 19.963 & 0.9801 & -0.0998 & 0.8611 & 70.140 & 0.8057 & 10.000 & 0.0020 & 0.9775 \\
\hline $\mathrm{F}-\mathrm{HDL} / 3$ & 17.213 & 0.8572 & -0.0740 & 0.7601 & 64.646 & 0.9303 & 0.6502 & 0.0080 & 0.9517 \\
\hline $\mathrm{F}-\mathrm{HDL} / 4$ & 32.290 & 0.9606 & -0.0905 & 0.8243 & 115.980 & 0.8504 & 0.8673 & 0.0042 & 0.9655 \\
\hline $\mathrm{F}-\mathrm{HDL} / 5$ & 0.5333 & 0.9297 & -0.1362 & 0.9667 & 17.652 & 0.6488 & 16.398 & 0.00015 & 0.9999 \\
\hline F-HDL/6 & 12.534 & 0.9523 & -0.1253 & 0.9368 & 41.966 & 0.6849 & 14.318 & 0.0005 & 0.9952 \\
\hline $\mathrm{F}-\mathrm{HDL} / 7$ & 26.634 & 0.9903 & -0.1090 & 0.9201 & 92.204 & 0.7766 & 11.328 & 0.0036 & 0.9958 \\
\hline $\mathrm{F}-\mathrm{HDL} / 8$ & 18.899 & 0.5787 & -0.0587 & 0.6551 & 74.225 & 0.9398 & 0.4729 & 0.0213 & 0.9136 \\
\hline F-HDL/9 & 39.807 & 0.4290 & -0.0540 & 0.6699 & 159.475 & 0.9536 & 0.4091 & 0.0193 & 0.9579 \\
\hline $\mathrm{F}-\mathrm{HDL} / 10$ & 43.248 & 0.5322 & -0.0571 & 0.6906 & 170.654 & 0.9652 & 0.4435 & 0.0229 & 0.9568 \\
\hline F-HDL/1 1 & 36.623 & - & -0.0443 & 0.5516 & 150.531 & 0.8302 & 0.3072 & 0.1923 & 0.9126 \\
\hline F-HDL/12 & 0.5221 & 0.9903 & -0.1090 & 0.9201 & 18.074 & 0.7766 & 0.5699 & 0.8025 & 0.9849 \\
\hline
\end{tabular}


Table 4. Estimated kinetic parameters of drug release (Acid medium).

\begin{tabular}{|c|c|c|c|c|c|c|c|c|c|}
\hline \multirow{3}{*}{ Sample } & \multicolumn{9}{|c|}{ Kinetic model } \\
\hline & \multicolumn{2}{|c|}{ Zero-order } & \multicolumn{2}{|c|}{ First-order } & \multicolumn{2}{|c|}{ Higuchi } & \multicolumn{3}{|c|}{ Korsmeyer-Peppas } \\
\hline & $\mathrm{K}_{\mathrm{z}}$ & $R^{2}$ & $\mathrm{~K}_{\mathrm{F}}$ & $R^{2}$ & $\mathrm{~K}_{\mathrm{H}}$ & $R^{2}$ & $n$ & $K_{p}$ & $R^{2}$ \\
\hline $\mathrm{F}-\mathrm{HDL} / 1$ & 43.692 & 0.9411 & -0.0894 & 0.7985 & 157.343 & 0.8421 & 0.8498 & 0.00675 & 0.9466 \\
\hline F-HDL/2 & 45.234 & 0.6826 & -0.0631 & 0,7098 & 175.482 & 0.9593 & 0.5142 & 0.0174 & 0.9426 \\
\hline $\mathrm{F}-\mathrm{HDL} / 3$ & 33.221 & 0.6531 & -0.0616 & 0.6862 & 131.267 & 0.9507 & 0.5040 & 0.0231 & 0.9295 \\
\hline $\mathrm{F}-\mathrm{HDL} / 4$ & 62.338 & 0.2431 & -0.0494 & 0.5782 & 252.093 & 0.8817 & 0.3665 & 0.0315 & 0.8825 \\
\hline F-HDL/5 & 13.437 & 0.9347 & -0.1300 & 0.9388 & 44.588 & 0.6569 & 15.344 & 0.0005 & 0.9922 \\
\hline F-HDL/6 & 30.492 & 0.9813 & -0.1108 & 0.9099 & 104.789 & 0.7541 & 11.823 & 0.0025 & 0.9912 \\
\hline F-HDL/7 & 55.844 & 0.9409 & -0.0812 & 0.8581 & 206.272 & 0.9347 & 0.7256 & 0.0232 & 0.9931 \\
\hline F-HDL/8 & 19.172 & 0.9912 & -0.0945 & 0.8907 & 68.498 & 0.8580 & 0.9127 & 0.0066 & 0.9941 \\
\hline F-HDL/9 & 40.160 & 0.2631 & -0.0503 & 0.6435 & 161.743 & 0.9241 & 0.3636 & 0.0208 & 0.9612 \\
\hline $\mathrm{F}-\mathrm{HDL} / 10$ & 60.571 & 0.5198 & -0.0569 & 0.7122 & 239.354 & 0.9746 & 0.4343 & 0.0328 & 0.9755 \\
\hline F-HDL/1 1 & 36.930 & - & -0.0439 & 0.5715 & 151.728 & 0.8236 & 0.2923 & 0.2004 & 0.9534 \\
\hline $\mathrm{F}-\mathrm{HDL} / 12$ & 32.217 & 0.1917 & -0.0486 & 0.6063 & 130.497 & 0.8956 & 0.3500 & 0.0293 & 0.9327 \\
\hline
\end{tabular}

priority kinetic mechanism of fluoride products 1-4, originating from the same precursor and synthesis conditions, comprised non-Fick behavior. However, F-LDH-2 and -4 presented a release of Case II and Fick in neutral and acid media, respectively. Products -5 to -8 all followed Super Case II, excluding a neutral medium F-LDH-8, which presented Fickian behavior. In the acid medium, two products, F-LDH-7 and -8, switched the release kinetics to non-Fick. Among products -9 to -12 , only F-LDH-12 in the neutral medium showed non-Fick behavior. All other products followed the Fick behavior in the two media.

Regarding the fluoride release kinetic mechanism, Fick-like formulations characterization of slow fluoride diffusion through the F-LDH outer layer was observed. ${ }^{34}$ The non-Fick mechanism comprises F-LDH swelling and relaxation, and fluoride diffusion. For Case II or Super Case II, fluoride release is related to matrix swelling, diffusion, and erosion. A more marked release occurs in these phases due to matrix internal chain breakage, resulting in an easier $\mathrm{F}^{-}$release. ${ }^{35}$

Based on the results, the medium type and synthesis conditions affected the F-release kinetics. Although the F-LDH-11 and F-LDH-7 products presented a higher $\mathrm{F}^{-}$release \%, F-LDH-8, synthesized at $40^{\circ} \mathrm{C}$ for $24 \mathrm{~h}$, showed better fluoride release performance in the acid medium according to Fick's kinetic adjustment, in neutral medium to non-Fick in acid medium. Dental demineralization and remineralization processes are characterized by the critical $\mathrm{pH}$ of the medium. Although the expensive process develops in acidic $\mathrm{pH}$, remineralization is activated when the $\mathrm{pH}$ is higher than $4.5 .{ }^{36}$ To obtain a product with dental application potential, F-LDH, selective for the acid medium, is suggested as dental caries development occurs in an acidic medium (critical $\mathrm{pH}=5.5$ ).

Thus, focusing on the clinical application of fluoridated LDHs, these formulations have good prospects as specific agents for patients at risk of developing caries. They can be used as a powdered product isolated or embedded in dental materials, such as dental varnishes, orthodontic cement, composite resins, toothpaste, and mouthwash. ${ }^{15}$ As caries is a biofilm and sugar-dependent disease affecting people of varying socioeconomic levels, easy-to-obtain and low-cost fluoride products are promising for good prophylactic therapy. ${ }^{37}$

Further research is needed to assess the behavior of these new materials in artificial saliva (in vitro experiments), which is a limitation of this study. Future research should address the material behavior in oral environments by applying in situ and in vivo models. This in vitro study shows the 
latent material qualities as a fluoride reservoir in dental materials.

\section{Conclusions}

F-LDHs were successfully synthesized and characterized in this study, thus providing a new approach to nanometric materials with potential application in dentistry for the prevention and control of dental caries. The F-LDH-8 product synthesized at $40^{\circ} \mathrm{C}$ for $24 \mathrm{~h}$ demonstrated the best fluoride release performance in the acidic medium. F-LDHs are a promising material for the prevention and control of dental caries, owing to the continuous fluoride ion release in the oral environment.

\section{Acknowledgments}

The authors thank the National Council for Scientific and Technological Development (CNPq/ Brazil), the Coordination for Improvement of Higher Education Personnel (CAPES/Brazil), the Foundation for Research Support of the State of Alagoas (FAPEAL/ Brazil), and the Financier of Studies and Projects (Finep/Brazil).

\section{References}

1. Kassebaum NJ, Bernabé E, Dahiya M, Bhandari B, Murray CJ, Marcenes W. Global burden of untreated caries: a systematic review and metaregression. J Dent Res. 2015 May;94(5):650-8. https://doi.org/10.1177/0022034515573272

2. Buzalaf MA. Review of fluoride intake and appropriateness of current guidelines. Adv Dent Res. 2018 Mar;29(2):157-66. https://doi.org/10.1177/0022034517750850

3. Nguyen S, Escudero C, Sediqi N, Smistad G, Hiorth M. Fluoride loaded polymeric nanoparticles for dental delivery. Eur J Pharm Sci. 2017 Jun;104(15):326-34. https://doi.org/10.1016/j.ejps.2017.04.004

4. Wang LS, Gupta A, Rotello VM. Nanomaterials for the treatment of bacterial biofilms. ACS Infect Dis. 2016 Jan;2(1):3-4. https://doi.org/10.1021/acsinfecdis.5b00116

5. Mishra G, Dash B, Pandey S. Layered double hydroxides: A brief review from fundamentals to application as evolving biomaterials. Appl Clay Sci. 2018 Mar;153(1):172-86. https://doi.org/10.1016/i.clay.2017.12.021

6. Cunha VR, Ferreira CA, Constantino VR, Tronto J, Valim JB. [Layered double hydroxides: Inorganic nanoparticles for storage and release of species of biological and therapeutic interest]. Quim Nova. 2010 Nov;33(1):159-71. Portuguese. https://doi.org/10.1590/S0100-40422010000100029

7. Kameda T, Oba J, Yoshioka T. New treatment method for boron in aqueous solutions using Mg-Al layered double hydroxide: kinetics and equilibrium studies. J Hazard Mater. 2015 Aug;293(15):54-63. https://doi.org/10.1016/i.jhazmat.2015.03.015

8. Kameda T, Oba J, Yoshioka T. Continuous treatment of boron and fluoride in aqueous solutions using a column loaded with granulated Mg-Al layered double hydroxides intercalated with nitrates. J Water Process Eng. 2015 Dec;8(3):195-201. https://doi.org/10.1016/j.jwpe.2015.10.009

9. Batistella L, Venquiaruto LD, Di Luccio M, Oliveira JV, Pergher SB, Mazutti MA, et al. Evaluation of acid activation under the adsorption capacity of double layered hydroxides of Mg-Al-CO3 type for fluoride removal from aqueous medium. Ind Eng Chem Res. 2011 Apr;50(11):6871-6. https://doi.org/10.1021/ie101020r

10. Lima E, Pfeiffer H, Flores J. Some consequences of the fluorination of brucite-like layers in layered double hydroxides: adsorption. Appl Clay Sci. 2014 Feb;88-89:26-32. https://doi.org/10.1016/i.clay.2013.12.011

11. Iguchi S, Teramura K, Hosokawa S, Tanaka T. Photocatalytic conversion of CO2in water using fluorinated layered double hydroxides as photocatalysts. Appl Catal A. 2016 Jul;521(5):160-7. https://doi.org/10.1016/i.apcata.2015.11.023

12. Fan J, $\mathrm{Xu} Z \mathrm{Z}$, Zheng S. Comment on "Factors influencing the removal of fluoride from aqueous solution by calcined Mg-Al-CO3 layered double hydroxides". J Hazard Mater. 2007 Jan;139(1):175-7. https://doi.org/10.1016/i.jhazmat.2006.07.004

13. Watanabe Y, Ikoma T, Yamada H, Stevens GW, Moriyoshi Y, Tanaka J, et al. Formation of hydroxyapatite nanocrystals on the surface of Ca-al-layered double hydroxide. J Am Ceram Soc. 2010 Apr;93(4):1195-200. https://doi.org/10.1111/j.1551-2916.2010.03576.x

14. Lynch RJ. Zinc in the mouth, its interactions with dental enamel and possible effects on caries; a review of the literature. Int Dent J. 2011 Aug;61(3 Suppl 3):46-54. https://doi.org/10.1111/i.1875-595X.2011.00049.x

15. Hoxha A, Gillam DG, Bushby AJ, Agha A, Patel MP. Layered double hydroxide fluoride release in dental applications: a systematic review. Dent J (Basel). 2019 Sep;7(3):E87. https://doi.org/10.3390/dj7030087 
16. Benício LP, Silva RA, Lopes JA, Eulálio D, Santos RM, Aquino LA, et al. Layered double hydroxides: nanomaterials for applications in agriculture. Rev Bras Ciênc Solo. 2015 Feb;39(1):1-13. https://doi.org/10.1590/01000683rbcs2015081

17. Chen M, Cooper HM, Zhou JZ, Bartlett PF, Xu ZP. Reduction in the size of layered double hydroxide nanoparticles enhances the efficiency of siRNA delivery. J Colloid Interface Sci. 2013 Jan;390(1):275-81. https://doi.org/10.1016/i.jcis.2012.09.033

18. Tammaro L, Vittoria V, Calarco A, Petillo O, Riccitiello F, Peluso G. Effect of layered double hydroxide intercalated with fluoride ions on the physical, biological and release properties of a dental composite resin. J Dent. 2014 Jan;42(1):60-7. https://doi.org/10.1016/i.jdent.2013.10.019

19. Taves DR. Separation of fluoride by rapid diffusion using hexamethyldisiloxane. Talanta. 1968 Sep;15(9):969-74. https://doi.org/10.1016/0039-9140(68)80097-9

20. Whitford GM. The metabolism and toxicity of fluoride. 2nd ed. Basel: Karger; 1996.

21. Silva FDSCM, Duarte RM, Sampaio FC. Fluoride release and uptake by glass ionomer cements. Rev Gaucha Odontol 2010 Dez;58(4):437-443

22. Bouaziz Z, Soussan L, Janot JM, Jaber M, Ben Haj Amara A, Balme S. Dual role of layered double hydroxide nanocomposites on antibacterial activity and degradation of tetracycline and oxytetracyline. Chemosphere. 2018 Sep;206:175-83. https://doi.org/10.1016/i.chemosphere.2018.05.003

23. Yue X, Liu W, Chen Z, Lin Z. Simultaneous removal of $\mathrm{Cu}(\mathrm{II})$ and $\mathrm{Cr}(\mathrm{VI})$ by Mg-Al-Cl layered double hydroxide and mechanism insight. J Environ Sci (China). 2017 Mar;53:16-26. https://doi.org/10.1016/i.jes.2016.01.015

24. ÖzgümüşS, Gök MK, Bal A, Güçlü G. Study on novel exfoliated polyampholyte nanocomposite hydrogels based on acrylic monomers and Mg-Al-Cl layered double hydroxide: synthesis and characterization. Chem Eng J. 2013 May;223(1):277-86. https://doi.org/10.1016/i.cej.2013.02.098

25. Lima E, Martínez-Ortiz MJ, Gutiérrez Reyes RI, Vera M. Fluorinated hydrotalcites: the addition of highly electronegative species in layered double hydroxides to tune basicity. Inorg Chem. 2012 Jul;51(14):7774-81. https://doi.org/10.1021/ic300799e

26. Moriyama S, Sasaki K, Hirajima T. Effect of freeze drying on characteristics of Mg-Al layered double hydroxides and bimetallic oxide synthesis and implications for fluoride sorption. Appl Clay Sci. 2016 Nov;132-133:460-7. https://doi.org/10.1016/i.clay.2016.07.016

27. Wu G, Wang X, Chen B, Li J, Zhao N, Wei W, et al. Fluorine-modified mesoporous Mg-Al mixed oxides: mild and stable base catalysts for O-methylation of phenol with dimethyl carbonate. Appl Catal A. 2007 Oct;329(1):106-11. https://doi.org/10.1016/i.apcata.2007.06.031

28. Xu X, Ling L, Wang R, Burgess JO. Formulation and characterization of a novel fluoride-releasing dental composite. Dent Mater. 2006 Nov;22(11):1014-23. https://doi.org/10.1016/i.dental.2005.11.027

29. Elhalil A, Qourzal S, Mahjoubi FZ, Elmoubarki R, Farnane M, Tounsadi H, et al. Defluoridation of groundwater by calcined Mg/Al layered double hydroxide. Emerg Contam. 2016 Mar;2(1):42-8. https://doi.org/10.1016/i.emcon.2016.03.002

30. Choudary BM, Bharathi B, Venkat Reddy C, Lakshmi Kantam M. The first example of heterogeneous oxidation of secondary amines by tungstate-exchanged Mg-Al layered double hydroxides: a green protocol. Green Chem. 2002 May;4(3):279-84 https://doi.org/10.1039/b202141m

31. Cury JA, Tenuta LM. Enamel remineralization: controlling the caries disease or treating early caries lesions? Braz Oral Res. 2009;23 Suppl 1:23-30. https://doi.org/10.1590/S1806-83242009000500005

32. Cury JA, Oliveira BH, Santos AP, Tenuta LM. Are fluoride releasing dental materials clinically effective on caries control? Dent Mater. 2016 Mar;32(3):323-33. https://doi.org/10.1016/i.dental.2015.12.002

33. Donato RK, Luza L, Silva RF, Moro CC, Guzatto R, Samios D, et al. The role of oleate-functionalized layered double hydroxide in the melt compounding of polypropylene nanocomposites. Mater Sci Eng C. 2012 Dec;32(8):2396-403. https://doi.org/10.1016/i.msec.2012.07.013

34. Kim AR, Lee SL, Park SN. Properties and in vitro drug release of $\mathrm{pH}$ - and temperature-sensitive double cross-linked interpenetrating polymer network hydrogels based on hyaluronic acid/poly ( $\mathrm{N}$-isopropylacrylamide) for transdermal delivery of luteolin. Int J Biol Macromol 2018 Oct;118(A):731-40. https://doi.org/10.1016/i.ijbiomac.2018.06.061

35. Jaipal A, Pandey MM, Charde SY, Sadhu N, Srinivas A, Prasad RG. Controlled release effervescent buccal discs of buspirone hydrochloride: in vitro and in vivo evaluation studies. Drug Deliv. 2016;23(2):452-8. https://doi.org/10.3109/10717544.2014.917388

36. Ten Cate JM, Buzalaf MA. Fluoride mode of action: onde there was an observant dentist... J Dent Res. 2019 Jul;98(7):725-30. https://doi.org/10.1177/0022034519831604

37. Pollick H. The role of fluoride in the prevention of tooth decay. Pediatr Clin North Am. 2018 Oct;65(5):923-40. https://doi.org/10.1016/i.pcl.2018.05.014 